Ni Wayan Cika Pratiwi, I Wayan Wiarta, I Gusti Ayu Agung Sri Asri. (2020). Model Pembelajaran Quick On The Draw Berbasis Kearifan Lokal Tri Hita Karana Berpengaruh terhadap Kompetensi Pengetahuan Matematika. Jurnal Penelitian dan Pengembangan Pendidikan. Vol. 4 (3) pp. 371-378.

\title{
Model Pembelajaran Quick On The Draw Berbasis Kearifan Lokal Tri Hita Karana Berpengaruh terhadap Kompetensi Pengetahuan Matematika
}

\author{
Ni Wayan Cika Pratiwi1 ${ }^{*}$, I Wayan Wiarta², I Gusti Ayu Agung Sri Asri ${ }^{3}$ \\ 123 Program Studi Pendidikan Guru Sekolah Dasar Universitas Pendidikan Ganesha, Singaraja, Indonesia
}

\begin{abstract}
Abstrak
Penelitian ini bertujuan untuk mengetahui pengaruh model pembelajaran Quick

Kata Kunci:

On The Draw berbasis kearifan lokal Tri Hita Karana terhadap kompetensi pengetahuan matematika siswa kelas IV SD. Jenis penelitian yang digunakan yaitu eksperimen semu Quick On Draw, Tri Hita Karana, Matematika dengan bentuk desain nonequivalent control group design. Populasi yang dilibatkan adalah seluruh kelas IV SD sebanyak 246. Sampel penelitian ditentukan dengan teknik cluster random sampling dengan sampel secara keseluruhan ialah 55 siswa. Teknik pengumpulan data menggunakan tes kompetensi pengetahuan matematika. Data yang terkumpul dinormalisasikan menggunakan gain skor kemudian dianalisis menggunakan uji-t polled varians. hasil analisis data, diperoleh $\mathrm{t}_{\text {hitung }}=3,305>\mathrm{t}_{\text {tabel }}=2,005$ dengan $\mathrm{dk}=53$ pada taraf signifikansi $5 \%$. Sehingga $\mathrm{H}_{0}$ ditolak, maka terdapat pengaruh yang signifikan model pembelajaran Quick On The Draw berbasis kearifan lokal Tri Hita Karana terhadap kompetensi pengetahuan matematika kelas IV SD yang disebabkan karena pembelajaran dengan model pembelajaran Quick On The Draw berbasis kearifan lokal Tri Hita Karana mampu meningkatkan kompetensi pengetahuan matematika melalui langkah-langkah pembelajaran yang dapat melatih siswa lebih aktif dan optimal dalam memahami pelajaran matematika.
\end{abstract}

\begin{abstract}
This study aims to determine the effect of the Tri Hita Karana-based Quick On The Draw learning model on the mathematical knowledge competence of fourth grade elementary school students. The type of research used is quasi-experimental Keywords:

Quick On Draw, Tri Hita Karana, Mathematical design with nonequivalent control group design. The population involved was all grade IV elementary schools totaling 246. The study sample was determined by cluster random sampling technique with a total sample of 55 students. Data collection techniques using mathematics knowledge competency tests. The collected data is normalized using the gain score and then analyzed using the polled variance t-test. the results of data analysis, obtained tcount $=3.305>$ ttable $=2.005$ with $\mathrm{dk}=53$ at a significance level of $5 \%$. So $\mathrm{HO}$ is rejected, then there is a significant influence of the Tri Hita Karana based on local wisdom Tri Hita Karana learning model on the fourth grade elementary school mathematical knowledge competency caused by learning with the Quick On The Draw learning model based on local wisdom Tri Hita Karana is able to improve the competence of mathematical knowledge through learning steps that can train students to be more active and optimal in understanding mathematics.
\end{abstract}

\footnotetext{
* Corresponding author. 


\section{PENDAHULUAN}

Pembelajaran kurikulum 2013 dilaksanakan melalui pendekatan saintifik. Pendekatan saintifik ini diberikan kepada siswa agar siswa paham dalam mengenal, memahami berbagai materi menggunakan pendekatan ilmiah, bahwa informasi dapat berasal dari mana saja. (Devina et al., 2017) pendidikan saintifik adalah suatu pendekatan pembelajaran yang mengutamakan temuan siswa sehingga siswa secara kreatif dan aktif mengonstruk konsep dan prinsip. (Dewi et al., 2020) menyatakan kurikulum merupakan dasar dari penyelenggaraan pendidikan. Kurikulum 2013 lebih menekankan pada kompetensi berbasis sikap, pengetahuan, dan keterampilan.

Pembelajaran matematika ialah proses pembelajaran yang dikembangkan oleh guru dalam membangkitkan kreativitas berpikir siswa yang mampu memperluas pemikiran siswa dan meningkatkan keahliannya dalam membangun pengetahuan baru (Kurniyanthi et al., 2017). (Indradewi et al., 2017) belajar matematika merupakan suatu syarat utama melanjutkan pendidikan, karena dengan belajar matematika kita belajar menalar secara kritis, kreatif, dan aktif. (Dewi et al., 2017) menyatakan tujuan umum pembelajaran matematika pada jenjang pendidikan dasar adalah menyiapkan agar siswa sanggup menghadapi perubahan keadaan didalam kehidupan dan didunia yang selalu berkembang. Pemberian matematika di jenjang sekolah dasar, selain untuk meningkatkan daya pikir logis, terstruktur, analitis, kreatif, kritis dan kebiasaan bekerjasama dalam menyelesaikan masalah (Krisnayanti et al., 2017). Matematika sangat penting dalam kehidupan sehari-hari, tetapi pada kenyataannya banyak siswa yang berpendapat matematika merupakan mata pelajaran yang menakutkan dan sulit untuk dipahami sehingga hal ini membuat minat siswa untuk belajar matematika rendah dan menyebabkan tingkat pencapaian siswa juga rendah.

Berdasarkan observasi dan wawancara yang dilakukan di kelas IV SD Gugus Ir. Soekarno Denpasar Selatan khususnya pada mata pelajaran matematika, siswa masih kurang aktif dan kurang optimal pemahamannya dalam pembelajaran matematika. Hal tersebut membuat 48 siswa masih mendapatkan nilai kurang dari Kriteria Ketuntasan Minimal (KKM) untuk pelajaran matematika yaitu 70. Yang artinya masih terdapat 19,51 \% siswa yang mengalami kesulitan dalam pembelajaran matematika di kelas IV SDN Gugus Ir. Soekarno Denpasar Selatan yaitu sebanyak 246 siswa. Kurang optimalnya siswa dalam memahami pelajaran matematika dikarenakan beberapa masalah dalam proses pembelajaran matematika, yakni siswa masih kurang dalam memahami konsep matematika karena kurang optimalnya penerapan pendekatan saintifik dan penerapan model-model pembelajaran yang inofatif dan siswa kurang berani untuk bertanya mengenai masalah-masalah yang belum dipahami ketika diberikan pertanyaan yang diberikan guru. (Prabaningrum et al., 2019) menyatakan terdapat faktor yang menyebabkan rendahnya kompetensi pengetahuan matematika yaitu proses pembelajaran belum optimal dari segi kompetensi pengetahuan siswa. (Yuliantari et al., 2016) menyatakan keberhasilan pembelajaran matematika dapat diukur dari keberhasilan siswa mengikuti kegiatan pembelajaran, keberhasilan itu dapat dilihat dari tingkat pemahaman, penguasaan materi, serta hasil belajar.

Bercermin dari permasalahan tersebut, diperlukan suatu upaya untuk meningkatkan kompetensi pengetahuan matematika siswa. (Putri et al., 2019) menyatakan banyak hal yang dapat dilakukan oleh guru untuk memvariasikan cara mengajar, salah satunya penggunaan model dalam proses pembelajaran. Adapun solusi yang tepat adalah dengan menerapkan model pembelajaran Quick On The Draw berbasis kearifan lokal Tri Hita Karana. (Ginnis, 2016) Model pembelajaran Quick On The Draw adalah model pembelajaran yang menginginkan agar siswa bekerja sama secara kooperatif pada kelompok-kelompok kecil dengan tujuan untuk menjadi kelompok pertama yang menyelesaikan satu set pertanyaan. (Ayu, Linda., 2018) model pembelajaran kooperatif tipe Quick On The Draw adalah salah satu tipe pembelajaran kooperatif yang mudah diterapkan yang melibatkan aktivitas seluruh siswa tanpa harus ada perbedaan status, melibatkan siswa sebagai tutor sebaya, dan mengandung unsur permainan dan penguatan.

Model pembelajaran Quick On The Draw yang awalnya berdiri sendiri akan disisipkan dengan nilai-nilai kearifan lokal yang ada di lingkungan sekitar siswa. (Ramdani, 2018) menyatakan kearifan lokal merupakan budaya yang dimiliki oleh masyarakat tertentu yang dianggap mampu bertahan dalam menghadapi arus globalisasi, karena kearifan lokal tersebut mengandung nilai-nilai yang dapat dijadikan sebagai sarana pembangunan karakter bangsa. (Suja, 2010:2) "kearifan lokal merupakan bagian dari kebudayaan yang mentradisi, menjadi milik kolektif, dan bersifat fungsional untuk memecahkan masalah, setelah melewati pengalaman dalam dimensi ruang dan waktu secara berkelanjutan". Kearifan lokal adalah gagasan-gagasan lokal yang bersifat bijaksana, bernilai, yang tertanam dan diikuti oleh warga masyarakat (Astami et al., 2016) .Terdapat berbagai macam kearifan lokal yang dimiliki oleh suatu daerah yang diwariskan dari generasi ke generasi, salah satunya yaitu Tri Hita Karana.Secara etimologis istilah Tri Hita Karana berasal dari kata "tri, hita dan karana".Tri artinya tiga, Hita artinya bahagia dan Karana artinya penyebab.Dengan demikian Tri Hita Karana berarti "tiga penyebab kebahagiaan" (Wiana, 2007) 
Tri Hita Karana terdiri dari 3 bagian yaitu Parahyangan, Pawongan dan Palemahan. (Putra et al., 2019) menyatakan bahwa dengan menerapkan tiga bagian Tri Hita Karana yang pertama yaitu Parahyangan, siswa akan terbiasa untuk berdoa sebelum dan sesudah pembelajaran berlangsung, kedua yaitu Pawongan, siswa akan terbiasa saling menghargai pendapat dan perbedaan dengan temannya sehingga suasana kelas menjadi harmonis, dan yang ketiga palemahan, siswa akan terbiasa untuk memanfaatkan lingkungannya dengan bijak dan menjaga lingkungannya supaya tetap asri dan lestari. Dengan demikian, proses belajar mengajar menggunakan pengimplementasian ajaran Tri Hita Karana akan membuat siswa lebih menghargai lingkungan sekitarnya, dan selalu beretika serta berkarakter yang baik.

Dengan menggunakan Model Pembelajaran Quick On The Draw berbasis kearifan lokal Tri Hita Karana siswa akan lebih aktif dalam menemukan, mengembangkan pengetahuannya, dan melaksanakan pembelajaran menggunakan etika yang baik yang nantinya akan menyebabkan terbinanya hubungan yang harmonis antara manusia dengan Tuhan, manusia dengan manusia, dan manusia dengan alam.

Model Pembelajaran Quick On The Drawberbasis kearifan lokal Tri Hita Karanasangat tepat dilaksanakan untuk muatan pelajaran matematik karena pelajaran matematika sering dianggap sulit oleh siswa. Pembelajaran matematika perlu suatu logika yang baik dan juga siswa mampu menemukan pemahamannya sendiri dan kemudian dapat berbagi ilmunya dengan sesama. Maka dari itu, Model Pembelajaran Quick On The Draw berbasis kearifan lokal Tri Hita Karana dapat membuat siswa belajar matematika dengan aktif, berpikir kritis secara lebih mudah serta menanamkan karakter siswa dalam menjaga keharmonisan dengan Tuhan, sesamanya, dan alam.

Berdasarkan atas keunggulan model pembelajaran Quick On The Draw berbasis kearifan lokal Tri Hita Karana, dapat mengoptimalkan proses pembelajaran Matematika. Pernyataan ini didukung oleh 2 penelitian, menurut (Tyas, 2017) hasil penelitian ini menunjukan bahwa nilai rata-rata post test kelas eksperimen sebesar 77,33 sedangkan kelas kontrol dengan nilai rata-rata post test sebesar 72,50. Persamaan penelitian tersebut terletak pada model pembelajaran Quick On The Draw pada kelas eksperimen. Sedangkan perbedaan penelitian terletak pada kompetensi pengetahuan, tempat penelitian, dan tahun penelitian.Kemudian menurut (Ani et al., 2017) Hal ini dibuktikan dengan thitung > ttabel diperoleh penguasaan kompetensi pengetahuan siswa kelompok eksperimen lebih tinggi dari kelompok kontrol yaitu 4,939 > 2,000. Persamaan penelitian terletak pada pembelajaran berbasis Tri Hita Karana. Sedangkan perbedaan penelitian terletak pada model pembelajaran, tahun penelitian, dan kompetensi pengetahuan. Dan menurut (Yunita et al., 2018) "Pengaruh Model Pembelajaran Kooperatif Tipe TGT Berbasis Kearifan Lokal Tri Hita Karana Terhadap Hasil Belajar" menyimpulkan bahwa adanya pengaruh terhadap kompetensi pengetahuan IPS siswa kelas IV SD Gugus II Kecamatan Bangli Kabupaten Bangli. Persamaan penelitian terletak pada pembelajaran berbasis Tri Hita Karana. Sedangkan perbedaan penelitian terletak pada model pembelajaran, tahun penelitian, dan kompetensi pengetahuan.

Perbedaan penelitian ini dengan penelitian lain yang sudah ada yaitu pada penelitian ini model pembelajaran Quick On The Draw akan dipadukan dengan konsep Tri Hita Karana. Dengan menerapkan model pembelajaran Quick On The Draw cenderung akan membuat siswa lebih aktif dalam proses pembelajaran sehingga untuk membuat siswa dapat mengendalikan dirinya selama proses pembelajaran maka dipadukanlah model ini dengan konsep Tri Hita Karana. Konsep Tri Hita Karana ini akan membuat siswa untuk saling menjaga hubungan-hubungan yang harmonis baik dengan tuhan, sesamanya dan juga terhadap lingkungannya. Tujuan yang ingin dicapai dari penelitian ini adalah untuk mendeskripsikan kompetensi pengetahuan matematika kelompok siswa yang dibelajarkan menggunakan model pembelajaran Quick On The Draw berbasis kearifan lokal Tri Hita Karana, untuk mendeskripsikan kompetensi pengetahuan matematika kelompok siswa yang dibelajarkan menggunakan pembelajaran konvensional, dan untuk mengetahui pengaruh yang signifikan model pembelajaran Quick On The Draw berbasis kearifan lokal Tri Hita Karana terhadap kompetensi pengetahuan matematika kelas IV SDN Gugus Ir. Soekarno Denpasar Selatan tahun ajaran 2019/2020.

\section{METODE PENELITIAN}

Dalam penelitian ini rancangan yang digunakan adalah rancangan eksperimen. Penelitian ini akan dilaksanakan pada semester II tahun pelajaran 2019/2020 di kelas IV SDN Gugus Ir. Soekarno Denpasar Selatan. Jenis penelitian yang digunakan adalah penelitian kuantitatif yaitu eksperimen semu (quasy experimental design) dengan desain non-equivalent control group design. Desain ini melibatkan 2 kelompok sampel, yaitu kelompok eksperimen dan kelompok kontrol.

Dalam penentuan subjek penelitian, langkah awal yang dilakukan dalam penelitian ini adalah menentukan populasi yang akan diteliti. (Setyosari, 2015) menyatakan populasi adalah seluruh kasus, objek ataupun orang yang dikaji pada penelitian. Populasi pada penelitian ini adalah seluruh kelas IV SDN Gugus Ir. Soekarno Denpasar Selatan Tahun Ajaran 2019/2020. (Agung, 2014) sampel merupakan 
sebagian dari populasi yang diambil. Sampel merupakan wakil populasi yang berupa kelompok kecil bagian dari populasi itu sendiri (Arsani et al., 2013). Sampel pada penelitian ini diambil dengan menggunakan teknik ClusterRandom Sampling dengan cara pengundian. Pengundian dilaksanakan sebanyak 2 kali. Pengundian pertama dilaksanakan untuk memperoleh kesetaraan kelas secara akademik, dilakukan uji prasyarat yaitu uji normalitas dan homogenitas untuk memenuhi syarat melakukan uji kesetaraan dengan uji-t. dan pengundian kedua dilaksanakan untuk mengetahui kelompok eksperimeen dan kelompok kontrol.

Pada penelitian ini data yang dikumpulkan adalah data kompetensi pengetahuan Matematika kelas IV SDN Gugus Ir. Soekarno Denpasar Selatan tahun pelajaran 2019/2020. Tes kompetensi pengetahuan matematika yang digunakan dalam penelitian ini adalah tes objektif dengan instrumen berbentuk tes objektif pilihan ganda biasa. Tes ini meliputi 4 pilihan jawaban yaitu a, b, c, dan d. setiap soal diberikan skor 1 jika dijawab dengan benar dan skor 0 jika dijawab salah. Skor setiap soal dijumlah dan hasilnya menjadi skor variabel penguasaan kompetensi pengetahuan matematika.

Teknik analisis statistik inferensial digunakan untuk menganalisis data pada penelitian ini. Maksud dari penggunaan statistik inferensial adalah untuk menguji hipotesis penelitian dengan teknik mengolah data dengan diterapkannya rumus statistika (Purwani et al., 2018). Statistik inferensial digunakan untuk menganalisis data gain skor yang dinormalisasikan dari hasil pre test dan post test.

Analisis data dilaksanakan dengan menggunakan uji-t dengan sebelumnya sudah melaksanakan uji prasyarat yaitu uji normalitas dan uji homogenitas. Uji normalitas dilakukan untuk mengetahui apakah sebaran data berdistribusi normal atau tidak, maka digunakan rumus Kolmogorov-Smirnov. Kriteria

pengujian pada taraf signifikansi $5 \%$ jika harga nilai maksimum $\left|F_{r}-F_{s}\right| \leq$ harga tabel KolmogorovSmirnov, maka $\mathrm{H}_{0}$ diterima dan data berdistribusi normal.Jika data berdistribusi normal, dilakukan uji

homogenitas varians dengaan uji F. Kriteria pengujian, jika $F_{\text {hit }}<F_{\text {tabel }}$ maka sampel homogen.Pengujian dilakukan pada taraf signifikansi 5\% $(\alpha=0,05)$ dengan derajat kebebasan untuk pembilang $\mathrm{n}_{1}-1$ dan derajat kebebasan untuk penyebut $\mathrm{n}_{2}-1$.

Apabila data sudah normal dan homogen, maka selanjutnya data dianalisis dengan menggunakan statistik parametrik. Uji hipotesis pada penelitian ini menggunakan uji -t dengan rumus polled varians.

Dengan kriteria jika harga $t_{\text {hitung }} \leq t_{\text {tabel }}$, maka $H_{0}$ diterima, dan jika harga $t_{\text {hitung }}>t_{\text {tabel, }}$, maka $H_{0}$ ditolak.

Pada taraf signifikansi 5\% $(\alpha=0,05)$ dengan $\mathrm{dk}=\mathrm{n}_{1}+\mathrm{n}_{2}-2$.

\section{ANALISIS DAN PEMBAHASAN}

Data hasil penelitian ini memaparkan mengenai perolehan hasil post-test pada kelompok eksperimen dan kelompok kontrol SDN Gugus Ir. Soekarno Denpasar Selatan Tahun Ajaran 2019/2020. Data yang diperoleh dalam penelitian ini dikelompokkan menjadi dua yaitu data kompetensi pengetahuan matematika kelompok eksperimen di SDN 2 Pedungan dan data kompetensi pengetahuan matematika kelompok kontrol di SDN 5 pedungan.

Penelitian dilakukan sebanyak 6 kali perlakuan di kelompok eksperimen dan kelompok kontrol. Diakhir pertemuan diberikan post-test. Kemudian data dari gain skor tersebut dianalisis sehingga diperoleh mean $(X)$, standar deviasi $(s)$, varians $\left(\mathrm{s}^{2}\right)$. Berikut rekapitulasi data posttest kelompok eksperimen dan kelompok kontrol.

Tabel 1. Rekapitulasi Data Posttest Kelompok Eksperimen dan Kelompok Kontrol

\begin{tabular}{lcc}
\hline \multicolumn{1}{c}{ Data } & Kelompok Eksperimen & Kelompok Kontrol \\
\hline Mean & 0.49 & 0.46 \\
Standar Deviasi & 0.20 & 0.18 \\
Varians & 0.04 & 0.03 \\
Skor Minimum & 0.00 & 0.00 \\
Skor Maksimum & 0.87 & 0.86 \\
\hline
\end{tabular}

Pengujian hipotesis menggunakan rumus uji t polled varians. Namun sebelum uji t dilakukan, terlebih dahulu melakukan uji prasyarat analisis meliputi uji normalitas sebaran data dengan menggunakan rumus Kolmogorov-smirnov dan uji homogenitas varian dengan uji F. 
Tabel 2. Rekapitulasi Hasil Uji Normalitas Kelompok Eksperimen dan Kelompok Kontrol

\begin{tabular}{lccc}
\hline \multicolumn{1}{c}{ Sampel } & $\begin{array}{c}\text { Nilai Maksimal } \\
|F T-F S|\end{array}$ & $\begin{array}{c}\text { Harga Kritis } \\
\text { Kolmogorov-Smirnov }\end{array}$ & Keterangan \\
\hline $\begin{array}{l}\text { Kelompok Eksperimen } \\
\text { Kelompok }\end{array}$ & 0,1830 & 0,264 & Berdistribusi Normal \\
Kontrol & 0,110 & 0,242 & Berdistribusi Normal \\
\hline
\end{tabular}

Data Gain Skor Kelompok Eksperimen, diperoleh nilai maksimum $|F T-F S|=0,183$ sedangkan untuk nilai tabel Kolmogorov-Smirnov $(\alpha=0,05)=0,264$ karena Nilai tabel Kolmogorov-Smirnov $(\alpha=$ $0,05)=0,264>$ nilai maksimum $|F \mathrm{~T}-F S|=0,183$ maka sebaran data gain skor kelompok eksperimen berdistribusi normal. Berdasarkan perhitungan hasil uji normalitas sebaran data gain skor siswa di kelas Kontrol, diperoleh nilai maksimum $|F T-F S|=0,110$ sedangkan untuk nilai tabel Kolmogorov-Smirnov $(\alpha$ $=0,05)=0,242$ karena nilai tabel Kolmogorov-Smirnov $(\alpha=0,05)=0,242>$ nilai maksimum $|F T-F S|=$ 0,110 maka sebaran data gain skor siswa kelompok kontrol berdistribusi normal.

Setelah data berdistribusi normal, dilanjutkan dengan melakukan uji homogenitas varian. Rekapitulasi hasil homogenitas varian, disajikan pada tabel berikut.

Tabel 3. Rekapitulasi Hasil Uji Homogenitas Kelompok Eksperimen dan Kelompok Kontrol

\begin{tabular}{lcccc}
\hline \multicolumn{1}{c}{ Sampel } & Varians & DK & F $_{\text {hitung }}$ & $\mathbf{F}_{\text {tabel }}$ \\
\hline Kelompok & 0,04 & 24 & 1,3 & 1,9 \\
Eksperimen & 0,03 & 29 & & \\
Kelompok Kontrol & & & \\
\hline
\end{tabular}

Berdasarkan hasil analisis diperoleh diperoleh $\mathrm{f}_{\text {hitung }}=1,3$ sedangkan untuk taraf signifikansi $5 \%$ $F_{\text {tabel }}$ dengan dk pembilang 25-1 = 24 dan dk penyebut 30-1 = 29 adalah 1,9. Ini berarti $f_{\text {hitung }}=1,3<f_{\text {tabel }}=$ 1,9 maka data homogen.

Berdasarkan hasil uji normalitas dan homogenitas dapat diketahui bahwa data yang diperoleh dari kelompok eksperimen dan kelompok kontrol berdistribusi normal dan memiliki varians yang homogen. Karena data yang diperoleh telah memenuhi semua prasyarat, uji hipotesis dilakukan dengan menggunakan analisis uji-t. Adapun kriteria pengujiannya adalah apabila $t_{\text {hitung }}<\mathrm{t}_{\text {tabel }}$ maka $\mathrm{H}_{0}$ diterima. Sebaliknya apabila $t_{\text {hitung }} \geq t_{\text {tabel, }}$ maka $\mathrm{H}_{0}$ ditolak. Dengan $\mathrm{dk} n 1+\mathrm{n} 2-2$ dan taraf signifikansi $5 \%(\alpha=$ $0,05)$. Hipotesis yang diuji dalam penelitian ini adalah tidak terdapat perbedaan yang signifikan kompetensi pengetahuan matematika siswa yang dibelajarkan menggunakan model pembelajaran Quick On The Draw berbasis kearifan lokal Tri Hita Karana dengan yang dibelajarkan menggunakan pembelajaran konvensional pada kelas IV SDN Gugus Ir. Soekarno Denpasar Selatan Tahun Ajaran $2019 / 2020$.

Tabel 4. Rekapitulasi Hasil Analisis Uji-t Kelompok Sampel Penelitian

\begin{tabular}{lccccccc}
\hline \multicolumn{1}{c}{ Sampel Penelitian } & $\mathbf{N}$ & $\mathbf{d k}$ & $\mathbf{X ~ B a r}$ & $\mathbf{s}^{\mathbf{2}}$ & $\mathbf{t}_{\text {hitung }}$ & $\mathbf{t}_{\text {tabel }}$ & Keterangan \\
\hline $\begin{array}{l}\text { Kelompok } \\
\begin{array}{l}\text { Eksperimen } \\
\text { Kelompok Kontrol }\end{array}\end{array}$ & 25 & & 0.49 & 0.04 & & & \\
\hline
\end{tabular}

Berdasarkan hasil analisis menggunakan uji-t diperoleh thitung = 3,306 kemudian dibandingkan dengan $t_{\text {tabel }}$ dengan $\mathrm{dk}=25+30-2=53$ pada taraf signifikansi $5 \%$ diperoleh ttabel $=2,006$. Karena $t_{\text {hitung }}=3,306>t_{\text {tabel }}(\alpha=0,05)=2,006$, maka $\mathrm{H}_{0}$ ditolak. Hal ini berarti terdapat perbedaan yang signifikan kompetensi pengetahuan matematika siswa yang dibelajarkan menggunakan model pembelajaran Quick On The Draw berbasis kearifan lokal Tri Hita Karana dengan yang dibelajarkan menggunakan pembelajaran konvensional pada kelas IV SDN Gugus Ir. Soekarno Denpasar Selatan Tahun Ajaran $2019 / 2020$.

Berdasarkan perolehan Kompetensi pengetahuan Matematika pada kedua kelompok, dapat diketahui bahwa kedua kelompok mengalami perbedaan setelah diberikan treatment. Hasil rata-rata gain skor ternormalisasi kelompok eksperimen yaitu 0,49 dan kelompok kontrol yaitu 0,46. Maka hasil perolehan pada kelompok eksperimen lebih besar dibandingkan kelompok kontrol. Rata -rata gain skor ternormalisasi tersebut dikonversikan pada tabel PAN skala 5 (lima) dan diperoleh hasil kompetensi pengetahuan matematika kelompok eksperimen dan kelompok kontrol berada pada kategori cukup. Hal 
ini merupakan akibat dari pemberian treatment kepada kelompok eksperimen, yaitu dengan memberikan model pembelajaran Quick On The Draw berbasis kearifan lokal Tri Hita Karana. Pemberian treatmen di kelompok eksperimen berjalan dengan optimal sehingga siswa lebih aktif dan dapat memahami pelajaran matematika dengan baik sehingga pencapaian kompetensi pengetahuan matematika siswa mengalami peningkatan. (Nonitha et al., 2016) menyatakan pembelajaran konvensional yang diterapkan oleh guru akan membuat pola pikir siswa pasif, siswa hanya menerima informasi dari guru tanpa ada umpan balik terhadap informasi tersebut. Belajar dengan pembelajaran konvensioanl peserta didik hanya akan mendengarkan dan mencatat pokok-pokok penting yang dikemukakan oleh pengajar. Hal ini penyebab peserta didik menjadi pasif, kurang inisiatif, mudah jenuh, dan bergantung pada pengajar dalam pembelajaran. Akibatnya proses pembelajaran sulit diterima oleh siswa dan tingkat pemahaman siswa cenderung kurang dalam proses pembelajaran. Pembelajaran menggunakan model pembelajaran Quick On The Draw berbasis kearifan lokal Tri Hita Karana ini memiliki beberapa kelebihan yakni, (a) mendorong kerja kelompok semakin efisien, (b) membantu siswa untuk membiasakan diri untuk belajar pada sumber, tidak hanya pada guru, dan (c) sesuai dengan karakter siswa yang tidak dapat duduk diam selama lebih dari dua menit. Model pembelajaran Quick On The Draw merupakan model pembelajaran yang memberikan siswa kesempatan untuk berperan aktif dalam proses pembelajaran, karena dalam belajar siswa diajak untuk bekerjasama dalam kelompoknya untuk dapat menyelesaikan kartu soal yang diberikan oleh guru untuk menjadi kelompok pertama yang menjadi pemenangnya. (Aini, Septi Dariyatul., 2019) menyatakan pembelajaran ini disetting dalam suasana perlombaan dimana kelompok yang paling cepat menyelesaikan soal-soal secara tepat maka kelompok tersebut akan menjadi kelompok pemenang. (Saputra et al., 2017) unsur-unsur di dalam Tri Hita Karana harus dilaksanakan secara utuh dan terpadu di dalam pengimplementasiannya. Dengan melaksanakan pembelajaran berbasis kearifan lokal Tri Hita Karana siswa diajak untuk saling menghargai terhadap sekitarnya. (Jaya, 2019) menyatakan dalam proses pendidikan ajaran Tri Hita Karana merupakan sebuah konsep yang sangat momentum dan bersifat adiluhung dalam membangun keharmonisan yang penuh dengan nilai-nilai kebijakan, nilai norma, nilai etika, nilai persatuan sehingga terjadi kehidupan yang harmonis antara semua ciptaan tuhan. Dengan menerapkan pembelajaran berbasis Tri Hita Karana siswa akan mampu untuk saling menghargai, beretika, dan menjaga hubungan dengan semua ciptaan tuhan dengan baik.

Hasil penelitian ini didukung pula oleh (Nadia, 2019) yang menyimpulkan bahwa terdapat pengaruh yang signifikan pada penerapan model pembelajaran kooperatif tipe Quick On The Draw terhadap hasil belajar siswa. (Renja, A. N., 2018) menyimpulkan bahwa ada pengaruh penerapan model pembelajaran Quick On The Draw terhadap aktivitas belajar siswa. Penelitian lain yang mendukung yaitu dengan (Pradnyawathi et al., 2019) yang menyatakan bahwa terdapat pengaruh yang signifikan pada penerapan model berbasis Tri Hita Karana.

Model pembelajaran Quick On The Draw berbasis kearifan lokal Tri Hita Karana sesuai untuk diterapkan, karena siswa akan diarahkan untuk belajar bekerjasama dalam kelompoknya untuk menyelesaikan masalah-masalah yang diberikan guru dengan membuat siswa tetap saling menghargai perbedaan-perbedaan yang akan didapatkan selama proses pembelajaran berlangsung. Dan Model pembelajaran Quick On The Draw berbasis kearifan lokal Tri Hita Karana dapat direkomendasikan dalam membelajarkan siswa khususnya pada pelajaran matematika karena dapat menyebabkan siswa pada kelas eksperimen lebih aktif dan optimal dalam proses pembelajaran serta dapat memunculkan karakter yang dimilki siswa dalam meningkatkan kinerjanya dalam pembelajarn.

Jadi dapat diambil kesimpulan model pembelajaran Quick On The Draw berbasis kearifan lokal Tri Hita Karana berpengaruh secara signifikan terhadap kompetensi pengetahuan matematika kelas IV SDN Gugus Ir. Soekarno Denpasar Selatan tahun ajaran 2019/2020.

\section{KESIMPULAN}

Berdasarkan hasil perhitungan nilai rata-rata pengetahuan matematika pada kelompok eksperimen yang dibelajarkan dengan model pembelajaran Quick On The Draw berbasis kearifan lokal Tri Hita Karana lebih tinggi dari pada rata-rata kelompok kontrol yang dibelajarkan dengan pembelajaran konvensional. Berdasarkan paparan hasil penelitian dan pembahasan diatas, dapat disimpulkan bahwa pembelajaran dengan model pembelajaran Quick On The Draw berbasis kearifan lokal Tri Hita Karana berpengaruh terhadap pengetahuan matematika sehingga dapat meningkatkan pemahaman siswa. Berdasarkan hasil penelitian, adapun saran yang disampaikan kepada guru agar dapat menerapkan model pembelajaran Quick On The Draw berbasis kearifan lokal Tri Hita Karanasebagai alternatif pemilihan model pembelajaran khususnya dalam pelajaran matematika dan mata pelajaran lain pada umumnya, sehingga mampu mengoptimalkan hasil pembelajaran. Kepada kepala sekolah dapat dijadikan masukan berharga kepala sekolah selaku pengambil kebijakan yang nantinya kebijakan tersebut dapat 
memperlancar kegiatan pembelajaran. Dan kepada peneliti lain dapat dijadikan sebagai bahan bacaan untuk mendalami objek penelitian yang sejenis.

\section{DAFTAR PUSTAKA}

Agung, A. A. G. (2014) Metodologi Penelitian. Yogyakarta: Aditya Media Publishing.

Aini, Septi Dariyatul., I. S. (2019) "Numerical: Jurnal Matematika dan Pendidikan Matematika Strategi Pembelajaran Quick on the Draw untuk Meningkatkan Aktivitas dan Hasil Belajar Mahasiswa Pada Materi Interpolasi," 3(1), hal. 19-30. doi: 10.25217/numerical.v3i1.421.

Ani, Ni Kadek Kisri., Darsana, I Wyn., Asri, I. G. A. A. S. (2017) "Pengaruh Model Pembelajaran Time Token Berbasis Tri Hita Karana Terhadap Hasil Belajar Ips Siswa Kelas V," e-Journal Mimbar PGSD PGSD Universitas Pendidikan Ganesha, 5(2).

Arsani, Ni Wayan., Putra, D.B.K.N.S., Ardana, I. K. (2013) "Pengaruh Model Pembelajaran Course Review Horay Terhadap Hasil Belajar IPA Siswa Kelas IV," Mimbar PGSD, 1(3), hal. 2. Tersedia pada: https://ejournal.undiksha.ac.id/index.php/JJPGSD/article/view/1486/1347.

Astami, N. W. et al. (2016) "KOMPETENSI PENGETAHUAN IPS Universitas Pendidikan Ganesha Tujuan Pendidikan Nasional.

Ayu, E. Y., Linda, R. dan . A. (2018) "Penerapan Pembelajaran Quick on the Draw Pada Materi Laju Reaksi Untuk Meningkatkan Aktivitas Belajar Siswa," Jurnal Pendidikan Kimia Indonesia, 2(1), hal. 32. doi: $10.23887 /$ jpk.v2i1.14134.

Devina, Ni Luh Novita., Wiarta I W., Wiyasa, K. N. (2017) “Model Pembelajaran Kooperatif Tipe Scramble Berbantuan Bahan Manipulatif Pengetahuan Matematika," 1, hal. 133-140.

Dewi, A. T. Y. R., Negara, I. G. A. O. (2020) “Pengaruh Model Pembelajaran ( SAVI) Berbantuan Multimedia Terhadap Kompetensi Pengetahuan IPA," Mimbar PGSD, 8, hal. 40-49.

Dewi, N. L. F., Wiarta, I. W. dan Suniasih, N. W. (2017) "Pengaruh Model Pembelajaran Realistik Setting Kooperatif ( Resik ) Dipadukan Dengan Ice Breaking Terhadap Hasil Belajar Matematika Jurusan Pendidikan Guru Sekolah Dasar , FIP Universitas Pendidikan Ganesha," e-Journal PGSD Universitas Pendidikan Ganesha, 5(2), hal. 1-10.

Ginnis, P. (2016) Trik \& Taktik Mengajar Strategi Meningkatkan Pencapaian Pengajaran di Kelas. Jakarta: PT. Indeks.

indradewi, nyoman adi., Putra, I K. Adnyana., Abadi, I. B. G. S. (2017) "Numbered Head Together Berbantuan Media Ni Nyoman Adi Indradewi 1, I Ketut Adnyana Putra 2 , I B Gede Surya Abadi 3 Jurusan Pendidikan Guru Sekolah Dasar Universitas Pendidikan Ganesha Singaraja , Indonesia Pendidikan adalah proses secara optimal melalui."

Jaya, K. A. (2019) "Membangun Mutu Pendidikan Karakter Siswa Melalui Implementasi Ajaran Tri Hita Karana," Jurnal Penjaminan Mutu, 5(1), hal. 57. doi: 10.25078/jpm.v5i1.759.

Krisnayanti, N. K. D., Wiarta, I. W. dan Negara, I. G. A. O. (2017) “Pengaruh Model Pembelajaran Inkuiri Terbimbing Berbantuan Tutor Sebaya Terhadap Kompetensi Pengetahuan Matematika Siswa Kelas V," e-journal PGSD Universitas Pendidikan Ganesha, 5(2), hal. 3.

kurniyanthi, N. M. F., Wiarta, I. W., \&Darsana, I. W. (2017) “Pengaruh Model Pembelajaran Kooperatif Tipe Snowball Throwing Berbantuan Lagu Daerah Terhadap Kompetensi Pengetahuan Matematika Universitas Pendidikan Ganesha." 
Nadia, F. (2019) "Pengaruh Model Pembelajaran Kooperatif Tipe Quick On The Draw terhadap Hasil Belajar Siswa pada Tema Panas dan Perpindahannya Kelas V SDN 35 Pagambiran. Program," Ejurnal bunghatta, 23(3), hal. 2019.

Nonitha, N.C.A., Sedanayasa, Gede., Japa, I. G. . (2016) “Lebih Besar Dari T,” 19(1), hal. 1-10.

Nym, N. dan Pradnyawathi, Chintya., Agustika, G. N. S. (2019) "Pengaruh Model Pakem Berbasis Tri Hita Karana terhadap Keterampilan Menulis," 3(1), hal. 89-98.

Prabaningrum, I.G.A. Inten., Putra, I. . K. A. (2019) "Pengaruh Model Pembelajaran Kooperatif Tipe Jigsaw Berbantuan Media Powerpoint Terhadap Kompetensi Pengetahuan PPKn," Media Komunikasi FPIPS, 17(1), hal. 405-413. doi: 10.23887/mkfis.v17i1.22196.

Purwani, N.P.R., Darsana I W., Manuaba, I. B. . (2018) "Pengaruh Model Pembelajaran Picture and Picture Berbasis Karakter Terhadap Kompetensi Pengetahuan Ips," Journal for Lesson and Learning Studies, 1(2), hal. 165-172. doi: 10.23887/jlls.v1i2.14714.

Putra, I W Weda Gustana., Parmiti, Desak Putu., S. I. W. (2019) "Pengaruh Model Pembelajaran Problem Based Learning Berorientasi Tri Hita Karana Terhadap Hasil Belajar Ipa Siswa Kelas V," Jurnal Pendidikan Multikultural Indonesia, 1(2), hal. 51. doi: 10.23887/jpmu.v1i2.20771.

Putri, N. M. C. N. M., Ardana, I. K. dan Agustika, G. N. S. (2019) "Pengaruh Model Discovery Learning Berbantuan Lingkungan Terhadap Kompetensi Pengetahuan IPA Siswa Kelas V," Mimbar PGSD, 7(2), hal. 57-64.

Ramdani, E. (2018) “"Pendidikan karakter merupakan tanggung jawab bersama. S," Jupiis: Jurnal Pendidikan Ilmu-Ilmu Sosial, 10(1), hal. 1. doi: 10.24114/jupiis.v10i1.8264.

Renja, A. N., M. (2018) "Pengaruh Penerapan Model Pembelajaran Quick on the Draw Terhadap Aktivitas Dan Hasil Belajar Kimia Siswa Pada Materi Hidrokarbon," Konfigurasi : Jurnal Pendidikan Kimia dan Terapan, 1(2), hal. 154. doi: 10.24014/konfigurasi.v1i2.4396.

Saputra, K. A., Atmadja, A. T. dan Sinarwati, N. K. (2017) "Memaknai Konsep Keseimbangan Komponen Tri Hita Karana Dalam Penganggaran Organisasi Subak ( Studi Kasus Pada Subak Kaliculuk, Desa Pakraman Dencarik, Kecamatan Banjar," 8(2).

Setyosari, P. (2015) Metode Penelitian Pendidikan dan Pengembangan. Jakarta: Prenamedia Group.

Suja, I. W. (2010) Kearifan Lokal Sains Asli Bali. Surabaya: Paramita.

Tyas, L. Y. (2017) “Pengaruh Model Quick On The Draw Didukung Media The Influence Of The Quick On The Draw Model Using Audiovisal Media On The Ability To Indentify Elements Of Folklore To Students At 5 Th Grade Of Sdn Burengan 2," 01(02).

Wiana, I. K. (2007) Tri Hita Karana Menurut Konsep Hindu. Surabaya: Paramita.

Yuliantari, N.P.E., Wiarta I W., Abadi, I. B. G. . (2016) "Penerapan Model Problem Based Learning Dapat Meningkatkan Keaktifan Dan Kompetensi Pengetahuan PKn Siswa Kelas V," e-Journal PGSD Universitas Pendidikan Ganesha Jurusan PGSD, 4(1).

Yunita, Ni Komang Devi., Tristiantari, N. K. D. (2018) "Pengaruh Model Pembelajaran Kooperatif Tipe Pair Check," Jurnal Penelitian Pendidikan Guru Sekolah Dasar, 6(6), hal. 96-107. 